\title{
Zukünftige Optionen zur Rekonstruktion bei ausgedehnten knöchernen Defekten im Kiefer-, Gesichts- und Schädelbe- reich mittels CAD/CAM-gefertigter bioaktiver Leitschienen
}

\author{
Florian Andreas Probst, Egon Burian, Riham Fliefel, Michael Ehrenfeld, Sven Otto
}

\section{Zusammenfassung}

Großdimensionierte knöcherne Defektsituationen stellen eine beträchtliche Herausforderung für die Mund-, Kiefer- und Gesichtschirurgie dar. Tissue-Engineering-(TE-)Anwendungen haben das Potenzial, in Zukunft eine vielversprechende Alternative zu autologen Regenerationstechniken zu sein. Derzeit gilt bspw. die Verwendung von Kompositscaffolds aus Tricalciumphosphat (TCP) und Polymeren sowie deren Besiedelung mit mesenchymalen Stammzellen oder Fettstammzellen als aussichtsreiche Tissue-Engineering-Strategie. CAD-CAM-Verfahren könnten dabei wesentlich dazu beitragen, die komplexe Morphologie des Gesichtsschädels zu rekonstruieren. Denkbare Indikationen zu TissueEngineering-Applikationen bestehen z.B. bei Kontinuitätsdefekten des Unterkiefers, Mittelgesichts- und Kalottendefekten sowie knöchernen Defekten des Kieferspaltbereichs.
Future Options for Reconstruction of Extensive Bony Defects in the Craniomaxillofacial Region Using CAD/CAM-Constructed Biological Scaffolds

Large bony defects represent a considerable challenge in craniomaxillofacial surgery. Tissue engineering applications have the ability to serve as an alternative solution to autologous bone transplants. Currently, the use of composite scaffolds made out of TCP or polymers and their subsequent seeding with stem cells can be considered a promising strategy. These stem cells are either derived from bone marrow or adipose tissue. CAD-CAM procedures strongly contribute to reconstruction of the complex craniofacial morphology. Possible indications for TE applications in craniomaxillofacial surgery can be segmental defects of the mandible as well as defects of the mid-face and calvaria.

\section{Ausgedehnte knöcherne Defekte: klinische Herausforderung und Behandlungsstrategien}

Großdimensionierte knöcherne Defekte in der Kiefer-, Gesichts- und Schädelregion beeinträchtigen in vielen Fällen sowohl Funktion als auch Aussehen betroffener Patienten. Dies kann soweit gehen, dass die Gesellschaftsfähigkeit dieser Patienten stark eingeschränkt wird [10, 23]. Die Behandlung solch ausgedehnter Defekte bringt eine Reihe von Schwierigkeiten mit sich $[10,26]$.

OP-JOURNAL 2013; 29: 200-204

(C) Georg Thieme Verlag KG Stuttgart · New York DOI http://dx.doi.org/10.1055/s-0033-1350664
Wird eine Rekonstruktion bei großvolumigen, nicht mehr von alleine heilenden Defekten, sog. „Critical-Size-Defekten“ notwendig, gilt nach wie vor die autologe Knochentransplantation als Goldstandard. Mit der Verpflanzung körpereigenen Knochengewebes gehen allerdings etliche Nachteile einher [13]. So resultiert bspw. eine teils erhebliche Morbidität im Bereich der Spenderregion. Zudem kann es vorkommen, dass ausreichende Gewebevolumina nicht zur Verfügung gestellt werden können [4]. Eine weitere Herausforderung ist die Wiederherstellung der komplexen Morphologie des Gesichtsschädelbereichs, da diese durch körpereigene Knochentransplantate meist nur unzureichend rekonstruiert werden kann. Obwohl seit längerer Zeit eine Reihe verschiedener Knochenersatzmaterialien, wie Hydro- xylapatit oder demineralisierte Knochenmatrix (DBX) verfügbar sind $[1,2]$, ist derzeit keines davon zur hinreichenden Regeneration ausgedehnter Knochendefekte im klinischen Alltag geeignet.

Verfahren des Bone Tissue Engineering stellen eine aussichtsreiche Alternative nicht nur zu konventionellen Knochenersatzmaterialien, sondern auch zu autologen Regenerationstechniken dar.

Beim Tissue Engineering wird das zur Regeneration einer bestimmten Region benötigte Knochengewebe künstlich angezüchtet. Dies erfolgt in vitro, d.h. außerhalb des Organismus. Einem Patienten wird dabei zunächst ein bestimmtes Gewebe wie Knochenmark oder Fettgewebe entnommen. Anschließend werden die benötigten Zellen, z.B. mesenchymale Stammzellen oder Fettstammzellen, isoliert. Nach Kultivierung und Differenzierung der Zellen in die Zielzellen, z. B. Osteoblasten und Vorläufer, erfolgt die Besiedelung einer Matrix (Leitschiene, Scaffold). Letztlich kann die Reimplantation der zellbesiedelten Matrix in den Organismus erfolgen und das gewünschte Gewebe regeneriert werden (Abb. 1).

Als die wichtigsten Bestandteile des Tissue Engineering von Knochengewebe gelten allgemein (Abb. 2):

- Zellen (z.B. Osteoblasten und Vorläuferstufen, insbesondere Stammzellen) $[7,8,14,29]$

- Mediatoren wie Wachstums- und Differenzierungsfaktoren (z.B. bone morphogenetic proteins, BMPs) $[5,11]$

- eine entsprechende Matrix („Trägermaterial“, "Scaffold“, „Leitschiene“) $[31,33]$

- Die Vaskularisation des Konstrukts $[17,19]$.

Gegenüber autologen Transplantaten haben Tissue-Engineering-Konstrukte den Vorteil des Wegfalls bzw. der Vermin- 


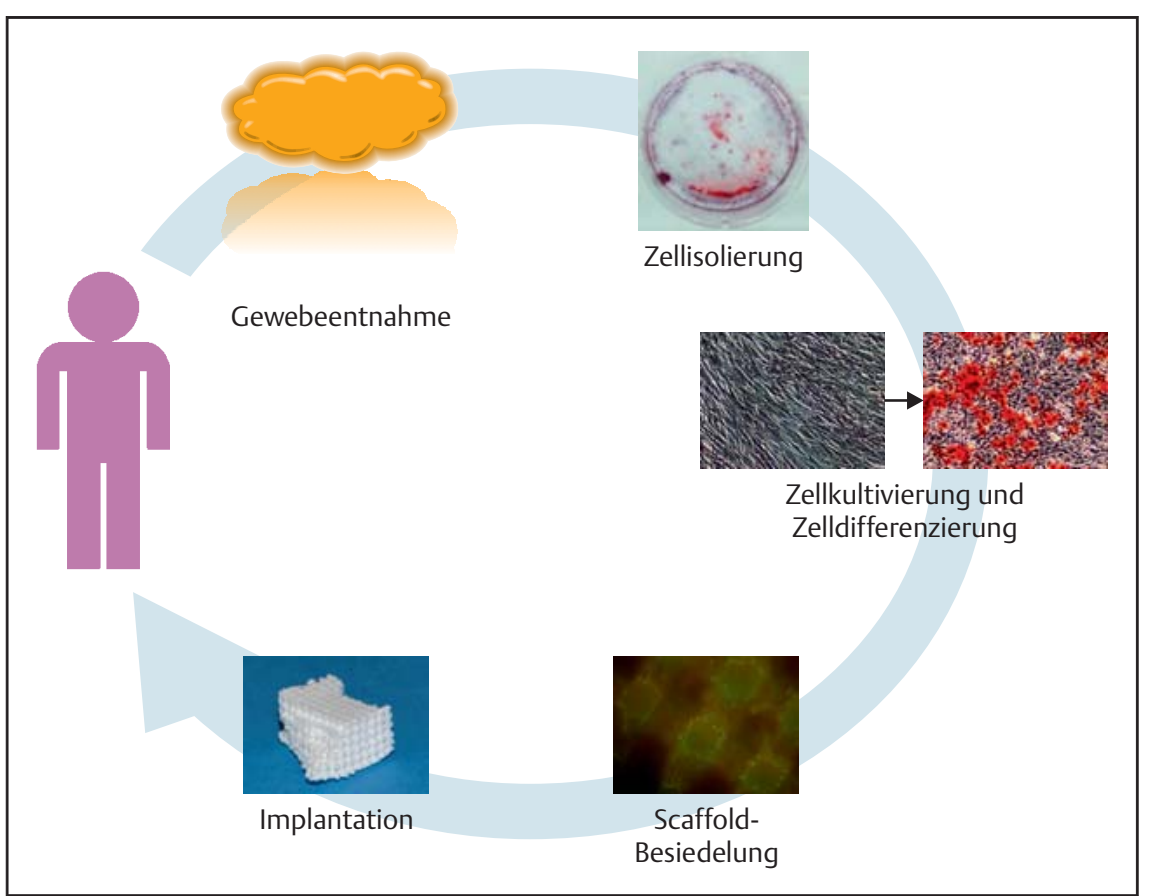

Abb. 1 Prinzip des Tissue Engineering.

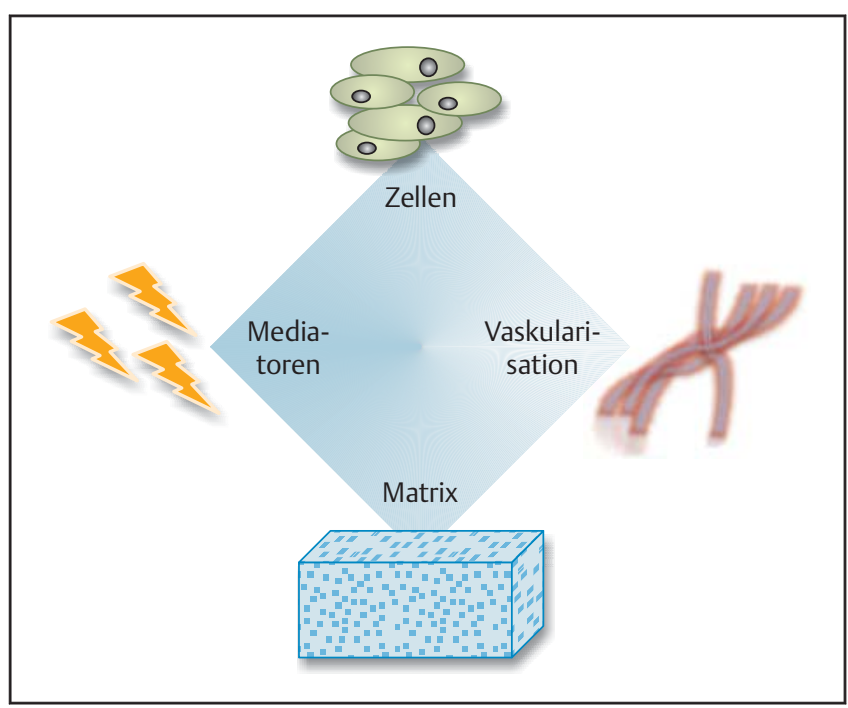

derung der Entnahmemorbidität und den Vorteil des theoretisch unbegrenzten Gewebereservoirs. Zudem ergibt sich als Vorteil im Vergleich zu konventionellen Knochenersatzmaterialien, dass autoregenerative Prozesse stimuliert werden und das anfänglich integrierte zellbesiedelte Konstrukt zugunsten körpereigenen Gewebes mit der Zeit ersetzt werden kann. Dies gilt insbesondere für bioresorbierbare Materialien.

\section{Zellen}

Derzeit sind bereits 3-dimensionale Gerüste als Trägermaterialien verfügbar, die in Kombination mit angesiedelten
Abb. 2 Elementare Bestandteile des Tissue Engineering.

- Nabelschnurstammzellen (umbilical cord mesenchymal stem cells, UCMSCs)

- Fettgewebsstammzellen (adipose-derived stem cells, ASCs)

- induzierte pluripotente Stammzellen (induced pluripotent stem cells, iPSCs)

- Perioststammzellen (periosteum-derived stem cells, PSCs)

- Stammzellen der Zahnpulpa (dental pulp-derived stem cells, DPSCs)

- Osteoprogenitorzellen (trabecular bone progenitor cells, TBPs)

[30,34].

\section{Matrix}

Hinsichtlich der Beschaffenheit von Trägermaterialien (auch Matrix, Scaffold oder Leitschiene) ist sowohl deren chemische Zusammensetzung als auch deren Oberflächen- und Binnenstruktur von Bedeutung. In den letzten Jahren ergab sich zunehmend eine Tendenz zugunsten bioresorbierbarer Materialien [3]. Diese gewährleisten anfänglich eine ausreichende lokale Stabilität und werden während des Heilungsprozesses kontinuierlich zugunsten des sich erholenden Gewebes resorbiert [22,25,37]. Somit werden keine Sekundäreingriffe zur Materialentfernung notwendig. Zudem sind interne Implantatwanderungen oder Interferenzen bei bildgebenden Verfahren nicht zu erwarten. Oberflächen- und Binnenstruktur sollten die natürlichen knöchernen Gegebenheiten naturgetreu nachbilden, damit Gerüste als Leitschienen zur Knocheneubildung dienen und die Neovaskularisation fördern können. Dies wird bspw. durch solche Gerüste erreicht, die eine poröse, vollständig miteinander verbundene Geometrie aufweisen. Kompositgerüste, die zum einen aus Keramiken wie Tricalciumphosphat (TCP) und zum anderen aus Polymeren wie z. B. Polycaprolactonsäure (PCLA), Polylactid-co-Glycolidsäure (PLGA) oder Polyhydroxybutyrat (PHBA) zusammengesetzt sind, tragen den erwünschten Eigenschaften wie Biokompatibilität, initialer mechanischer Stabilität, Bioresobierbarkeit und geeigneter Architektur Rechnung [24,38].

zial osteon diese Zellen relativ leicht gewonnen werden können, müssen sie vor der klinischen Anwendung vermehrt werden, um auf Trägermaterialien in relevanten Mengen zu adhärieren und zu proliferieren. Folgende Zellen sind u.a. derzeit in der Diskussion:

- mesenchymale Knochenmarksstammzellen (bone marrow-derived mesenchymal stem cells, BMSCs)
Um die anspruchsvollen morphologischen Gegebenheiten im Kiefer-, Gesichts- und Schädelbereich nachahmen zu können, bietet sich der Einsatz von CAD/CAM-Verfahren an (Abb. 3).

Dabei erfolgt, nach 3-dimensionaler bildgebender Diagnostik, der Import und die Weiterverarbeitung der gewon- 


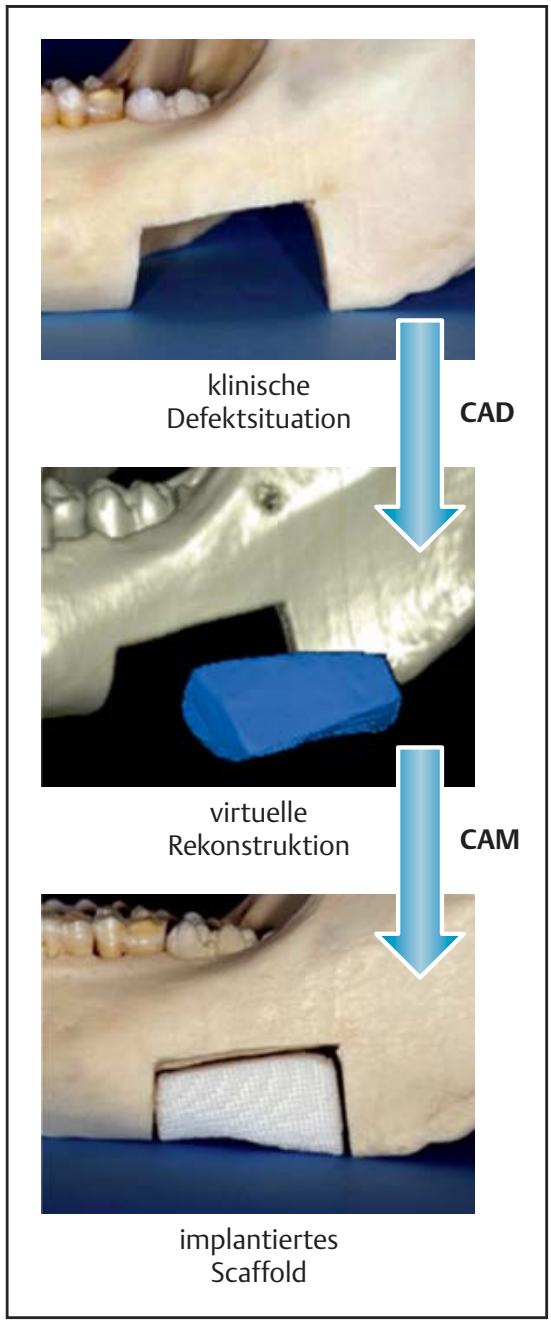

Abb. 3 Prinzip einer CAD-CAM-Rekonstruktion bei Vorliegen eines Unterkieferdefekts.

nen Daten in einem 3-D-Bildbearbeitungsprogramm. Hierfür hat sich u.a. das Programm MIMICS ${ }^{\circledR}$ der Firma Materialise (Leuven, Belgien) etabliert [16,21, 22]. Nach Segmentierung der Defektsituation wird ein virtuelles Gerüstmodell zur Rekonstruktion erstellt (Computer Aided Design, CAD). Anschließend wird auf Basis der generierten CAD-Daten das reelle Gerüstkonstrukt mittels RapidPrototyping-(RP-) Technologie gefertigt (Computer Aided Manufacturing, CAM). Zuvor muss der Datensatz zur Rekonstruktion noch in das Standardformat für Rapid-Prototyping-Fertigungen, das STL-Format, umgewandelt werden. Durch Rapid-Prototyping-Technologien ist es neben der anatomisch individualisierten Erstellung von Gerüsten auch möglich, Gerüstkonstrukte mit definierten Materialeigenschaften und bestimmter poröser Binnenarchitektur zu erstellen $[15,28,35]$.
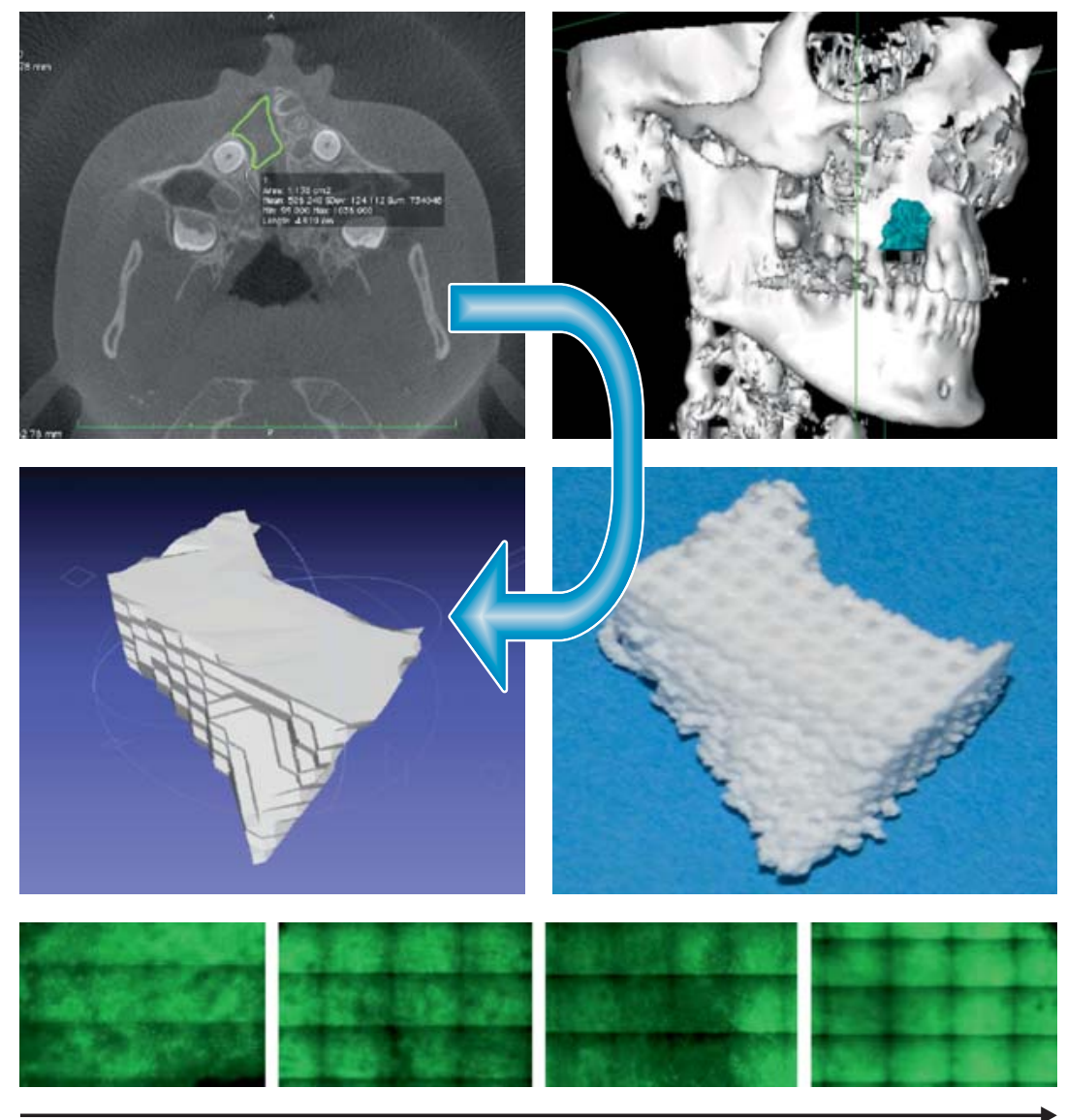

Abb. 4 Proof of Concept zur Durchführung einer sekundären Kieferspaltosteoplastik mittels eines CAD/CAM-gefertigten und zellbesiedelten (hBMSCs) Tricalciumphosphat/Polymer-Scaffold. Oben links: Segmentierung der Defektregion auf der Basis des routinemäßig durchgeführten DVT (Digitales Volumentomogramm). Oben rechts: 3-D-Ansicht des Gesichtsschädels mit virtueller Rekonstruktion (hellblau). Mitte rechts: virtuelle Rekonstruktion des Scaffolds. Mitte links: mittels Rapid Prototyping hergestelltes Scaffold. Unten von links nach rechts: fluoreszenzmikroskopische Darstellung der Zellproliferation auf dem Scaffold an Tag 1, 7, 14, 21 (von links nach rechts).

\section{Mediatoren}

Unter Mediatoren der Knochenregeneration sind im Allgemeinen Proteine zu verstehen, die als Wachstums- und Differenzierungsfaktoren agieren. Durch sie werden die Zellproliferation und die Differenzierung von Stamm- und Vorläuferzellen zu reifen somatischen Zellen angeregt. Die wichtigsten für die Knochenheilung bekannten Mediatoren sind BMPs (bone morphogenetic proteins), PDGF (platelet-derived growth factor), TGF-b, bFGF (basic fibroblast growth factor), IGF (insulin-like growth factor) und VEGF (vascular endothelial growth factor). Diese Proteine haben, dank ihres Einflusses auf knochenbildene Zellen, die Eigenschaft, neue Knochenbildung zu induzieren $[20,27]$.

Eine aussichtsreiche Alternative zur direkten Applikation von Wachstums- und Differenzierungsfaktoren ist die Bereitstellung entsprechender Proteine mittels Gentransfer. Über Genvektoren wird die genetische Information zur Herstellung der Signalproteine (BMP, TGF-b, VEGF etc.) in ortsständige Zellen eingeschleust (Transfektion). Anschließend werden die Signalproteine von den transfizierten Zellen, z.B. Fibroblasten, direkt am Ort der gewünschten Knochenneubildung hergestellt. Somit wirken die transfizierten Zellen quasi als endogener Bioreaktor [5]. Als Vorteile der Gentherapie können zum einen geringere Kosten und insbesondere die konstante und lang anhaltende Wirkung gegenüber der direkten Proteinanwendung vermutet werden.

\section{Vaskularisation}

In den letzten Jahren stellte sich immer mehr heraus, dass die Vaskularisation von Tissue-Engineering-Konstrukten ei- 


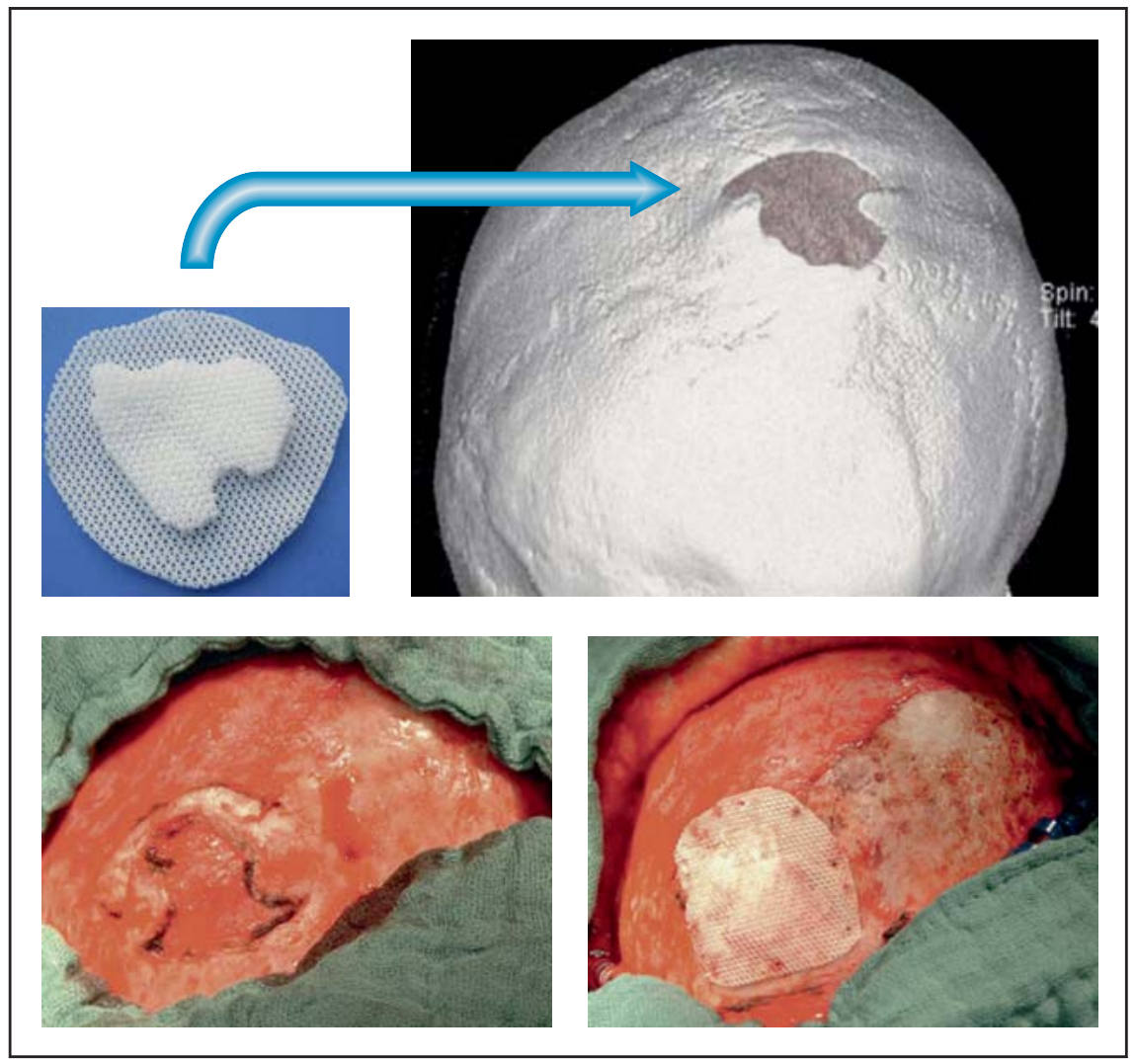

Abb. 5 Klinisches Beispiel für die Regeneration bei Vorliegen eines Kalottendefekts mittels eines CAD/CAM-gefertigten Poly- $\varepsilon$-Caprolacton/Tricalciumphosphat (PCL-TCP) Scaffold. Oben links: automatisiert hergestelltes Scaffold. Oben rechts: Defektregion in der 3-D-Rekonstruktion des präoperativen CT. Unten links: klinische Defektsituation. Untern rechts: in situ befindliches Scaffold (Aus: Probst FA, Hutmacher DW, Müller DF et al. Calvarial reconstruction by customized bioactive implant. Handchir Mikrochir Plast Chir 2010; 42: 369-373).

nen entscheidenden Faktor für die erfolgreiche gesteuerte Knochenregeneration darstellt. Dies liegt daran, dass die Versorgung von Zellen mit Sauerstoff und Nährstoffen sowie der Abtransport von Zellabfallprodukten eine wesentliche Rolle für das Überleben und die Proliferation der Zellen darstellt. Es existieren verschiedene Strategien zur Verbesserung der Vaskularisation beim Tissue Engineering von Knochengewebe:

- Einsatz funktionaler Scaffolds mit Kanälen und Mikroporen zur Förderung von Sauerstoff- und Nährstoffperfusion sowie zur Ausrichtung von Neogefäßen

- Verwendung angiogenetischer Wachstumsfaktoren wie PDGF (platelet-derived growth factor) oder VEGF (vascular endothelial growth factor)

- zellbasierter Ansatz mit Kokultur aus Endothelzellen, Osteoblasten sowie ggf. transfizierten mesenchymalen Stammzellen

- Verwendung von Bioreaktoren

- mikroelektromechanische Systeme, bei denen gefäßbaumartige Strukturen in einem Polymer angelegt werden und diese mit Endothelzellen besiedelt werden können
- Applikation mechanischer Stimuli

- arteriovenöse Loops (AV-Loops), die die Vaskularisation in vivo fördern $[17,19]$.

\section{Diskussion}

Tissue Engineering von Knochengewebe ist eine komplexe Herausforderung mit einer Vielzahl an Einflussvariablen. Dementsprechend reichlich sind die bisherigen Strategien einzelner Arbeitsgruppen auf diesem spannenden Teilgebiet der Regenerativen Medizin. Derzeit scheint noch nicht ersichtlich, welches Konzept letztlich den Durchbruch in vivo und somit in der klinischen Anwendung schaffen kann.

Um eine gewisse Formkonstanz für Rekonstruktionen im Gesichtsschädel zu gewährleisten, scheint die Matrix eines Kompositscaffolds, bspw. aus TCP/PLGA oder TCP/PCL, Erfolg versprechend. Hier besteht initial Formbeständigkeit. Die Bioresorbierbarkeit ermöglicht jedoch im zeitlichen Verlauf die vollständige Substitution der Matrix durch autoregenerierten Knochen. Bezüglich der Zell- auswahl zum Knochen-Tissue-Engineering sind derzeit mesenchymale Knochenmarkstammzellen (bone marrowderived mesenchymal stem cells, BMSCs) und zunehmend Fettgewebsstammzellen (adipose-derived stem cells, ASCs) beliebt $[30,34]$. BMSCs zeichnen sich durch ihre vergleichsweise einfache Gewinnungsmöglichkeit und ihr hohes osteogenes Potenzial aus. Im Rahmen des Tissue Engineering von Knochen wurden sie ausführlich untersucht und charakterisiert. Es lässt sich auch für die nächsten Jahre eine überragende Bedeutung der BMSCs vermuten. Eine bemerkenswerte Alternative stellen ASCs dar. Sie weisen ebenso die Fähigkeit auf, in Osteoblasten differenzieren $\mathrm{zu}$ können. Der große Vorteil der ASCs ist darin begründet, dass sie durch relativ minimalinvasive Eingriffe in großen Mengen bereitgestellt werden können. Zudem zeichnen sie sich durch eine hohe Toleranz gegenüber Sauerstoff- und Nährstoffmangel aus [18].

Aufgrund ihrer Widerstandsfähigkeit und der Möglichkeit zur einfachen und reichlichen Entnahme stellen ASCs (Fettgewebsstammzellen, adipose-derived stem cells) eine äußerst attraktive Option zur Besiedelung großer Tissue-Engineering-Konstrukte dar.

Was in der derzeitigen Diskussion noch unberücksichtigt bleibt ist, ob ein prinzipiell geeignetes Tissue-EngineeringKonstrukt, in der Übergangsphase von der Implantation bis zur vollständigen Umwandlung in Knochen, auch den biomechanischen Ansprüchen des Gesichtsschädels gerecht werden kann. Dies gilt in besonderem Maße für den Unterkieferbereich, da hier enorme Kaukräfte wirken. Des Weiteren wird für die klinische Anwendbarkeit wichtig sein, eine stabile und verlässliche Fixierungsmöglichkeit der Implantate zu gewährleisten. Konventionelle Osteosyntheseverfahren mögen für die Fixierung von Knochengewebe bestens geeignet sein, für die Fixierung bspw. eines keramikbasierten Scaffolds scheinen herkömmliche Osteosyntheseverfahren jedoch nur bedingt einsetzbar.

\section{Ausblick - Indikationen des Tissue Engineering in der MKG-Chirurgie}

Die komplexen morphologischen Strukturen im kraniomaxillofazialen Bereich stellen eine besondere Herausforderung beim Knochen-Tissue-Engineering dar. Wie bereits beschrieben könnten CAD/ 
CAM-Applikationen hier einen wertvollen Beitrag leisten. Bei folgenden klinischen Defektsituationen kann in $\mathrm{Zu}-$ kunft die Indikation für CAD/CAM-präfabrizierte und zellbesiedelte Scaffolds bestehen:

- Alveolarkammdefekte

- nicht knöchern konsolidierte Kieferspalten bei Kindern mit Lippen-Kiefer-Gaumenspalten (Abb. 4)

- Kalottendefekte (Abb.5)

- Mittelgesichts- und Orbitadefekte

- Unterkiefer-Kontinuitätsdefekte

\section{Literatur}

1 Burstein FD, Williams KJ, Hudgins R et al. Hydroxyapatite cement in craniofacial reconstruction: experience in 150 patients. Plast Reconstr Surg 2006; 118: 484-489

2 Chao MT, Jiang S, Smith D et al. Demineralized bone matrix and resorbable mesh bilaminate cranioplasty: a novel method for reconstruc tion of large-scale defects in the pediatric calvaria. Plast Reconstr Surg 2009; 123: $976-$ 982

${ }^{3}$ Chim H, Schantz JT. New frontiers in calvarial reconstruction: integrating computer-assisted design and tissue engineering in cranioplasty. Plast Reconstr Surg 2005; 116: $1726-$ 1741

${ }^{4}$ Davies JE, Baksh D. Bone Tissue Engineering and biodegradable Scaffolds. In: Ikada Y, Shimizu Y. Tissue Engineering for therapeutic Use. Amsterdam: Elsevier Science; 2000: 15

${ }^{5}$ Fischer J, Kolk A, Wolfart S et al. Future of local bone regeneration - protein versus gene therapy. J Craniomaxillofac Surg 2011; 39 : 54-64

${ }^{6}$ Griffin M, Iqbal SA, Bayat A. Exploring the application of mesenchymal stem cells in bone repair and regeneration. J Bone Joint Surg $\mathrm{Br}$ 2011: 93: 427-434

${ }^{7}$ Handschel J, Wiesmann HP, Depprich R et al. Cell-based bone reconstruction therapiescell sources. Int J Oral Maxillofac Implants 2006; 21: 890-898

8 Jayakumar P. Di Silvio L. Osteoblasts in bone tissue engineering. Proc Inst Mech Eng $\mathrm{H}$ 2010; 224: 1415-1440

9 Jones E, Yang X. Mesenchymal stem cells and bone regeneration: current status. Injury 2011; 42: 562-568

10 Kanatas AN, Mehanna HM, Lowe D et al. A second national survey of health-related quality of life questionnaires in head and neck oncology. Ann R Coll Surg Engl 2009; 91: 420-425

${ }^{11}$ Kempen DH, Creemers LB, Alblas $J$ et al. Growth factor interactions in bone regeneration. Tissue Eng Part B Rev 2010; 16: 551566

12 Lam CX, Hutmacher DW, Schantz JT et al. Evaluation of polycaprolactone scaffold degradation for 6 months in vitro and in vivo. J Biomed Mater Res A 2009; 90: 906-919

${ }^{13}$ Laurencin C, Khan Y, El Amin SF. Bone graft substitutes. Expert Rev Med Devices 2006 3: $49-57$
${ }^{14}$ Lee K, Chan CK, Patil $N$ et al. Cell therapy for bone regeneration-bench to bedside. J Biomed Mater Res B Appl Biomater 2009; 89: 252-263

15 Leukers B, Gulkan H, Irsen SH et al. Hydroxyapatite scaffolds for bone tissue engineering made by 3D printing. J Mater Sci Mater Med 2005; 16: 1121-1124

${ }^{16}$ Li WZ, Zhang MC, Li SP et al. Application of computer-aided three-dimensional skull model with rapid prototyping technique in repair of zygomatico-orbito-maxillary complex fracture. Int J Med Robot 2009; 5: 158163

17 Lovett M, Lee K, Edwards A et al. Vascularization strategies for tissue engineering. Tissue Eng Part B Rev 2009; 15: 353-370

18 Mischen BT, Follmar KF, Moyer KE et al. Metabolic and functional characterization of human adipose-derived SCs in tissue engineering. Plast Reconstr Surg 2008; 122: 725-738

${ }^{19}$ Nguyen LH, Annabi N, Nikkhah M et al. Vascularized bone tissue engineering: approaches for potential improvement. Tissue Eng Part B Rev 2012; 18: 363-382

20 Oringer RJ: Biological mediators for periodontal and bone regeneration. Compend Contin Educ Dent 2002; 23: 501-504, 506-510, 512 passim; quiz 518

21 Pham AM, Rafii AA, Metzger MC et al. Computer modeling and intraoperative navigation in maxillofacial surgery. Otolaryngol Head Neck Surg 2007; 137: 624-631

22 Probst FA, Hutmacher DW, Müller DF et al. Calvarial reconstruction by customized bioactive implant. Handchir Mikrochir Plast Chir 2010; 42: 369-373

${ }^{23}$ Rogers SN. Quality of life perspectives in patients with oral cancer. Oral Oncol 2010; 46: 445-447

${ }^{24}$ Swyer AA, Song SJ, Susanto E et al. The stimulation of healing within a rat calvarial defect by $\mathrm{mPCL}-\mathrm{TCP} /$ collagen scaffolds loaded with rhBMP-2. Biomaterials 2009; 30: 2479-2488

25 Schieker M, Seitz H, Seitz S et al. Biomaterials as scaffold for bone tissue engineering. Eur J Traum 2007: 32: 114-124

${ }^{26}$ Schieker M, Mutschler W. Die Überbrückung von posttraumatischen Knochendefekten. Unfallchirurg 2006; 109: 715-732

${ }^{27}$ Seeherman H, Wozney J, Li R. Bone morphogenetic protein delivery systems. Spine 2002; 27: S16-S23

${ }^{28}$ Seitz H, Rieder W, Irsen $S$ et al. Three-dimensional printing of porous ceramic scaffolds for bone tissue engineering. J Biomed Mater Res B Appl Biomater 2005; 74: 782-788

${ }^{29}$ Seong JM, Kim BC, Park JH et al. Stem cells in bone tissue engineering. Biomed Mater 2010; 5: 062001

30 Szpalski C, Barbaro M, Sagebin F et al. Bone tissue engineering: current strategies and techniques-part II: Cell types. Tissue Eng Part B Rev 2012; 18: 258-269

${ }^{31}$ Tanner KE. Bioactive composites for bone tissue engineering. Proc Inst Mech Eng H 2010; 224: 1359-1372

32 Wang L, Fan H, Zhang ZY et al. Osteogenesis and angiogenesis of tissue-engineered bone constructed by prevascularized $\beta$-tricalcium phosphate scaffold and mesenchymal stem cells. Biomaterials 2010; 31: 9452-9461
${ }^{33}$ Yeo A, Rai B, Sju E et al. The degradation profile of novel, bioresorbable PCL-TCP scaffolds: an in vitro and in vivo study. J Biomed Mater Res A 2008; 84: 208-218

${ }^{34}$ Zanetti AS, Sabliov C, Gimble JM et al. Human adipose-derived stem cells and three-dimensional scaffold constructs: a review of the biomaterials and models currently used for bone regeneration. J Biomed Mater Res B Appl Biomater 2013; 101: 187-199

${ }^{35}$ Zein I, Hutmacher DW, Tan KC et al. Fused deposition modeling of novel scaffold architectures for tissue engineering applications. Biomaterials 2002; 23: 1169-1185

${ }^{36}$ Zhang ZY, Teoh SH, Chong MS et al. Neo-vascularization and bone formation mediated by fetal mesenchymal stem cell tissue-engineered bone grafts in critical-size femoral defects. Biomaterials 2010; 31: 608-620

37 Zhao M, Zhou J, Li Xet al. Repair of bone defect with vascularized tissue engineered bone graft seeded with mesenchymal stem cells in rabbits. Microsurgery 2011; 31: 130-137

${ }^{8}$ Zhou Y, Hutmacher DW, Varawan S-L et al. In vitro bone engineering based on polycaprolactone and polycaprolactone-tricalcium phosphate composites. Polym Int 2007; 56: 333-342

\section{Egon Burian}

Doktorand ExperiMed

Dr. med. dent. Riham Fliefel

Postdoc ExperiMed

Prof. Dr. med. Dr. med. dent.

Michael Ehrenfeld

Direktor der Klinik

Dr. med. Dr. med. dent. Sven Otto

Oberarzt der Klinik, Mitglied Experi-

Med

Klinik und Poliklinik für Mund-, Kie-

fer- und Gesichtschirurgie

Klinikum der Universität München

Ludwig-Maximilians-Universität

München

Lindwurmstr. 2a

80337 München

\section{Dr. med. dent. Florian Andreas \\ Probst}

Assistenzarzt der Klinik,

Mitglied ExperiMed

Experimentelle Chirurgie und Regenerative Medizin (ExperiMed) an der Chirurgischen Klinik Innenstadt Ludwig-Maximilians-Universität München

Nussbaumstr. 20

80336 München

florian.probst@med.uni-muenchen.de 